
\title{
$\varepsilon_{\sin }$
}

Correspondence to

Professor Malcolm R Sears, McMaster University, Firestone Institute for Respiratory Health, St. Joseph's Healthcare Hamilton, 50 Charlton Avenue East, Hamilton, Ontario L8N 4A6, Canada; searsm@mcmaster.ca

Received 12 July 2012 Accepted 13 July 2012 Published Online First 2 August 2012

To cite: Sears MR. Thorax 2013;68:195-198.

\section{The FDA-mandated trial of safety of long-acting beta-agonists in asthma: finality or futility?}

\author{
Malcolm R Sears
}

In 2010, in response to a prolonged debate over the safety of long-acting beta-agonists (LABAs), the United States Food and Drugs Administration (FDA) issued guidelines for the use of LABAs in asthma, ${ }^{1}$ and mandated a very large trial examining the safety of LABAs used with concomitant inhaled corticosteroid (ICS). ${ }^{2}$ Strong voices have called for new safety data, ${ }^{3}{ }^{4}$ while others have expressed doubt regarding the need for, and likely outcomes of, new trials. ${ }^{56}$

\section{EVENTS LEADING TO THE FDA-CONCERNS OVER LABA SAFETY}

Controversy regarding safety has surrounded the use of long-acting beta-agonists in asthma virtually since salmeterol (Serevent, GlaxoSmithKline) was introduced into clinical practice in the UK in 1990 (figure 1). Studies showed greater control of asthma with addition of salmeterol to ICS compared with increased doses of $\operatorname{ICS}^{7} 8$ and reduced airway responsiveness to allergen challenge, which some interpreted as evidence of anti-inflammatory activity. ${ }^{9}$ The enthusiasm for salmeterol was dampened in 1993 when Castle et al published results from the large Serevent National Surveillance study showing a statistically insignificant $(p=0.10)$ but worrying threefold increase in mortality in patients prescribed regular salmeterol compared with regular salbutamol therapy. ${ }^{10}$

When salmeterol was launched in the US in 1994, the FDA required a post-marketing safety study. The Salmeterol Multicentre Asthma Research Trial (SMART) study began in 1996 but was terminated in 2003 with incomplete recruitment because of adverse outcomes on asthma exacerbations and mortality. ${ }^{11}$ Also in 2003, the FDA expressed concerns about increased exacerbations in adults and children using the Novartis formulation of inhaled formoterol in higher doses. ${ }^{12}$ In 2005, based on the salmeterol and formoterol trials, the FDA imposed a 'Black Box' warning on long-acting beta-agonists which continues in place today.

The FDA Pulmonary, Allergy Drugs Advisory Committee and the Paediatric Advisory Committee in 2005 and 2007 respectively, raised safety concerns related to outcomes of clinical trials of longacting beta-agonists. Although a post hoc analysis of the SMART study suggested that the excess deaths associated with salmeterol therapy were only evident among those not using ICS, this was not fully convincing as the data related only to ICS prescription at baseline, with no certainty of use of ICS during the trial itself. ${ }^{11}$
Fears regarding LABA safety were heightened further in 2006 when Salpeter et al published a meta-analysis, heavily weighted by data from the SMART trial, reporting the effect of LABAs on severe asthma exacerbations requiring hospitalisation, life-threatening asthma attacks and asthma-related deaths in adults and children. ${ }^{13}$ Randomised, placebo-controlled asthma trials of LABAs (salmeterol, formoterol, and eformoterol) with duration of more than 3 months were included in the meta-analysis, but those without placebo control groups were excluded. The authors suggested up to $80 \%$ of asthma deaths in USA could be attributed to salmeterol toxicity. ${ }^{14}$ This meta-analysis was extensively criticised ${ }^{15}{ }^{16}$ but nevertheless strongly influenced public opinion.

Following publication of the SMART study, many reviews and meta-analyses were conducted by academia and industry. Bateman et al ${ }^{17}$ reported data from 20966 participants in 66 studies of $>1$ week duration conducted by GlaxoSmithKline involving use of ICS with or without salmeterol examining asthma-related serious adverse events including hospitalisations and exacerbations requiring oral corticosteroids. Safety data relating to formoterol exposure in all AstraZeneca randomised, controlled, parallel-group asthma trials of 3-12 months duration involving formoterol were reported by Sears et $a l^{18}$ and further analysed by Nelson et $a .^{19} \mathrm{~A}$ meta-analysis of all studies in which formoterol or salmeterol was used with concomitant ICS was completed by Jaeschke et al. ${ }^{20}$ In each of these studies, the authors concluded that LABA use did not increase the risk of asthma-related oral steroid-requiring exacerbations or hospitalisations, but there were too few asthma deaths to establish the effect of LABA on mortality.

Rodrigo et al examined asthma exacerbations requiring systemic corticosteroids or hospitalisation, life-threatening exacerbations and asthma-related deaths in LABA trials, and reported that asthma related deaths were increased with LABA, but ICS provided a protective effect. ${ }^{21}$ LABA with ICS was equivalent to ICS in terms of life-threatening exacerbations and asthma related deaths, and significantly reduced exacerbations (OR $0.73,95 \%$ CI 0.67 to 0.79 ) and hospitalisations (O.R 0.58, 95\% CI 0.45 to 0.74). Cates et al compared adverse events in trials in which salmeterol was added to ICS, versus the same dose of ICS alone. ${ }^{22}$ Analysing 30 studies with 10873 participants, there were no differences in asthma-related deaths (OR 1.05, 95\% CI 0.32 to $3.47)$ or in asthma-related serious adverse effects (OR $0.95,95 \%$ CI 0.52 to 1.73 ). 


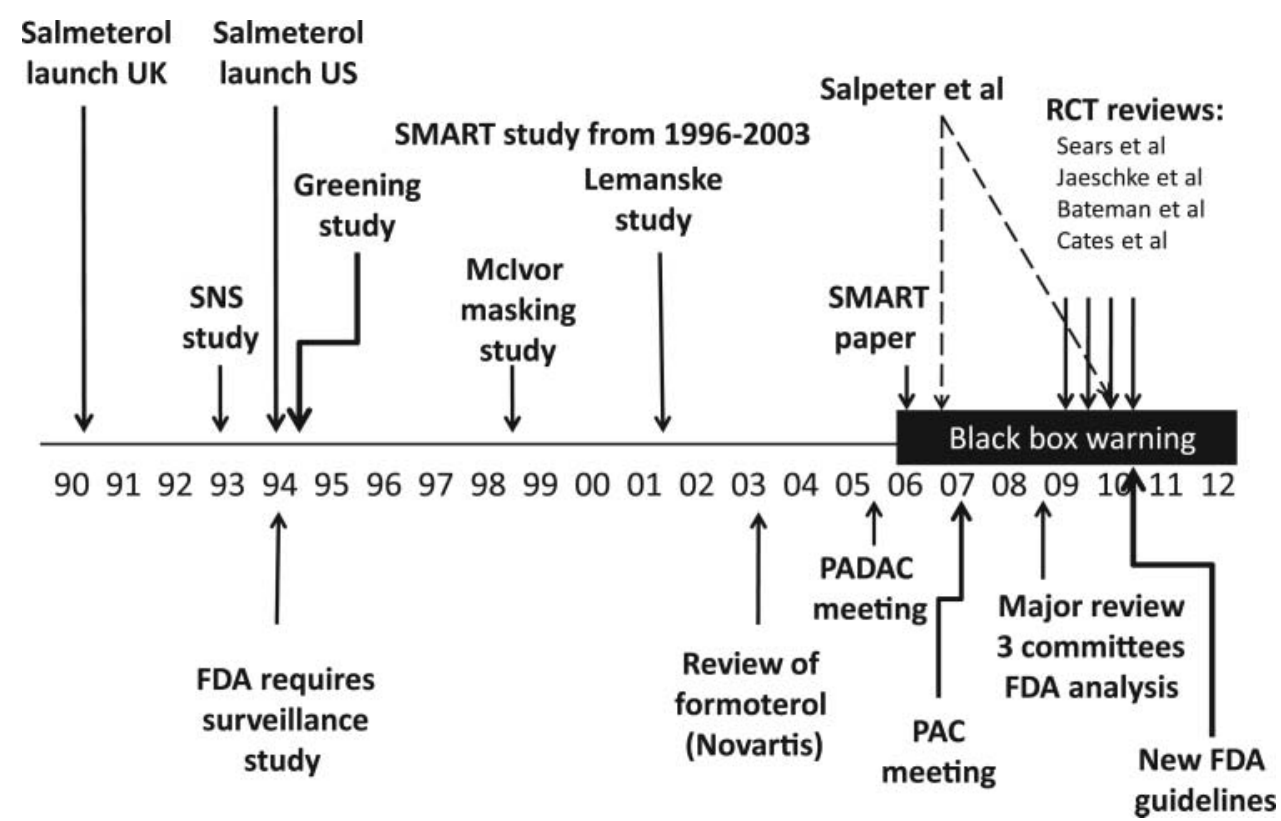

Figure 1 Timeline 1990-2012 of key long-acting beta-agonists (LABA) publications and Food and Drugs Administration (FDA) actions. FDA, Food and Drugs Administration; PAC, Paediatric Advisory Committee; PADAC, Pulmonary, Allergy Drugs Advisory Committee; RCT, randomised controlled trial; SMART, Salmeterol Multicentre Asthma Research Trial; SNS, Serevent National Surveillance.

\section{THE FDA META-ANALYSIS OF LABA SAFETY}

In 2008, in preparation for a major safety review requested by the Pulmonary, Allergy Drugs Advisory Committee and the Paediatric Advisory Committee, the FDA asked each of the pharmaceutical companies marketing LABA products in USA (AstraZeneca, GlaxoSmithKline and Novartis) to provide patient-based safety data from all blinded, parallel-arm, randomised, controlled trials conducted with LABAs in the treatment of asthma up to January 2008. The request included trials in which LABA was administered as randomised treatment, either with or without concomitant ICS or other adjunctive therapy, placebo-controlled and/or active-controlled trials, including trials in which there was a randomised blinded phase followed by an open label extension phase. For randomised, double-blind crossover design trials, only the first crossover period of the trial was included. Adverse events were blindly adjudicated for this meta-analysis.

Using data from 110 trials involving 60954 subjects, Levenson calculated risk differences (RD) for LABA versus non-LABA. ${ }^{23}$ The RD for asthma-related death was $0.40(95 \%$ CI 0.11 to 0.69 ) per 1000 subjects; 0.57 (95\% CI 0.01 to 1.12 ) for asthma-related death or intubation; and 2.57 (95\% CI 0.90 to 4.23) for asthma-related hospitalisation. For the composite outcome of all three end-points, the RD was 2.80 (95\% CI 1.11 to 4.49 ) (table 1).

Levenson also reported composite outcomes stratified by ICS use. ${ }^{23}$ For patients receiving LABA without mandatory randomised ICS, the RD was 3.63 (95\% CI 1.51 to 5.75 ), whereas among patients receiving LABA with mandatory ICS the RD was non-significant $(0.25$ : $95 \% \mathrm{CI}-1.69$ to 2.18 per 1000 subjects) compared with those using the same dose and formulation of ICS without LABA (table 1). Furthermore, 43 of 44 deaths and intubations in LABA-exposed patients occurred among 22 286 individuals $(0.19 \%)$ in trials which did not mandate the use of ICS compared with one among 7862 individuals (0.01\%) in trials with mandatory ICS. There were no deaths or intubations associated with treatment with single-device combinations of either salmeterol/fluticasone or formoterol/budesonide. This finding of no deaths associated with the combination salmeterol/ fluticasone was further confirmed by Weatherall et al among 22 600 patients. $^{24}$

\section{Can efficacy studies serve as safety studies?}

In 2010, Salpeter et al published a second disconcerting meta-analysis of existing data, reporting not only that LABA with or without ICS increased deaths and intubations more than twofold (OR 2.10, 95\% CI 1.37 to 3.22), but also that use of

Table 1 Risk differences for long-acting beta-agonists (LABA) versus non-LABA for asthma related-deaths, deaths and intubations, hospitalisations, and the composite outcome, reported in the Food and Drugs Administration (FDA) meta-analysis; data from Levenson table 5 and figure $1 .^{23}$ Reprinted from Sears MR, CHEST $2009^{5}$

\begin{tabular}{|c|c|c|c|}
\hline All trials & $\begin{array}{l}\text { LABA n/ } \\
\mathrm{N}^{*}\end{array}$ & $\begin{array}{l}\text { Non-LABA n/ } \\
\mathrm{N}^{*}\end{array}$ & $\begin{array}{l}\text { Risk differencet } \\
(95 \% \mathrm{Cl})\end{array}$ \\
\hline \multicolumn{4}{|c|}{ Risk differences for specific and composite outcomes } \\
\hline Asthma death & $\begin{array}{l}16 / 30 \\
148\end{array}$ & $4 / 30806$ & $\begin{array}{l}0.40(0.11 \text { to } \\
0.69)\end{array}$ \\
\hline Death or intubation & $\begin{array}{l}44 / 30 \\
148\end{array}$ & $27 / 30806$ & $\begin{array}{l}0.57(0.01 \text { to } \\
1.12)\end{array}$ \\
\hline Hospitalisation & $\begin{array}{l}369 / 30 \\
148\end{array}$ & 299/30 806 & $\begin{array}{l}2.57 \text { ( } 0.90 \text { to } \\
4.23)\end{array}$ \\
\hline $\begin{array}{l}\text { Composite outcome (death, } \\
\text { intubation or hospitalisation) }\end{array}$ & $\begin{array}{l}381 / 30 \\
148\end{array}$ & $304 / 30806$ & $\begin{array}{l}2.80(1.11 \text { to } \\
4.49)\end{array}$ \\
\hline \multicolumn{4}{|c|}{ Composite outcome stratified by use or non-use of randomised (mandatory) ICS } \\
\hline $\begin{array}{l}\text { Trials of LABA without } \\
\text { randomised ICS v no LABA }\end{array}$ & $\begin{array}{l}350 / 22 \\
286\end{array}$ & $279 / 24474$ & $\begin{array}{l}3.63(1.51 \text { to } \\
5.75)\end{array}$ \\
\hline $\begin{array}{l}\text { Trials of LABA with } \\
\text { randomised ICS v randomised ICS }\end{array}$ & $31 / 7862$ & $26 / 7330$ & $\begin{array}{l}0.25(-1.69 \text { to } \\
2.18)\end{array}$ \\
\hline \multicolumn{4}{|c|}{$\begin{array}{l}\text { ICS, inhaled corticosteroid. } \\
{ }^{*} n / N=\text { number of events } / \text { number at risk. } \\
\text { tRisk difference (RD) = additional risk of outcome per } 1000 \text { subjects treated with } \\
\text { LABA compared with no LABA; } 0.0 \text { indicates no increased risk. }\end{array}$} \\
\hline
\end{tabular}


concomitant ICS increased that risk to almost fourfold (OR $3.65,95 \%$ CI 1.39 to 9.55$){ }^{25}$ Even more alarming was the finding that LABA used with ICS as an integral part of the study intervention further increased the risk of deaths and intubations to eightfold above the risk of these events when using ICS alone (OR 8.19 , 95\% CI 1.10 to 16.18). These data differ markedly from those reported by the FDA in which LABA with mandatory ICS had no significant impact on safety outcomes. ${ }^{23}$

Critical appraisal of the outcomes reported by Salpeter et al strongly suggests confounding by ICS dose. Although Salpeter et al correctly exclude the five trials which did not require concomitant ICS (use ranged from $0 \%$ to $67 \%$ ), and report on data from seven trials or groups of studies ${ }^{26-31}$ in which ICS was used by all subjects, the fundamental error is that ICS doses were not necessarily equal between LABA and non-LABA study arms in those seven trials (table 2). Salpeter et al have unfortunately taken effectiveness studies designed to assess preferred treatments including higher and lower doses of ICS and used these as safety trials, not recognising that difference in outcomes likely reflects differences in doses of ICS. For a true assessment of safety of LABA, equal doses of ICS are required in each treatment arm with and without LABA to ensure any difference in safety signals reflect the addition of LABA. ${ }^{3}$ This critical fact has been clearly recognised and implemented in the FDA-mandated trial.

\section{What is the real safety issue?}

Is the issue really one of LABA safety due to intrinsic properties of LABAs, a worsening of disease by LABAs, or of potential for undertreatment with ICS? The concept has developed that LABAs are 'steroid-sparing', but this concept may be challenged. Lemanske et al reported that the dose of ICS could be reduced by $50 \%$ when salmeterol was added, despite a doubling of the rate of treatment failures in the group with lower ICS, because this doubling (OR 2.2) failed to achieve traditional statistical significance. ${ }^{32}$ Thomas et al, in a real world study in general practice in the UK, showed that increasing the dose of ICS gave better outcomes in terms of fewer exacerbations and courses of

Table 2 Review of inhaled corticosteroid (ICS) doses in seven trials reported by Salpeter et $a^{24}$ comparing long-acting beta-agonists (LABA) with ICS versus ICS alone

Trials comparing LABA + low dose ICS with higher dose ICS

Kelson et al, ICS group used twice the dose of beclomethasone

$1999^{26}$ compared with the LABA+ICS group

O'Byrne et al, ICS group used four times the dose of budesonide $2005^{27} \quad$ compared with the LABA+ICS group

Trials comparing LABA + ICS with both high and low doses ICS

Ind et al, $2003^{28} \quad$ LABA+ICS group used $250 \mu \mathrm{g}$ fluticasone; ICS group used either $250 \mu \mathrm{g}$ or $500 \mu \mathrm{g}$ fluticasone (approximately $50 \%$ used each dose)

O'Byrne et al, Both LABA+ICS groups and ICS groups used both $200 \mu \mathrm{g}$ and $400 \mu \mathrm{g}$ budesonide; unclear which dose was used in the fatal case

Trials with no information regarding ICS doses

GSK pooled Data for ICS use not provided, as not provided by GSK; trials, 2008 doses not specified or compared between LABA and non-LABA arms

\begin{tabular}{cl} 
Kemp et al, & Salmeterol or placebo was added to usual ICS; doses not \\
$1998^{30}$ & specified or compared between LABA and non-LABA arms \\
Von Berg et al, & $\begin{array}{l}\text { All patients were taking inhaled or oral corticosteroids; } \\
\text { doses not specified or compared between LABA and } \\
2003^{31} \\
\text { non-LABA arms }\end{array}$ \\
\hline
\end{tabular}

GSK, GlaxoSmithKline. oral corticosteroid than adding LABA. ${ }^{33}$ There is ample evidence that inadequate doses of ICS lead to more exacerbations, and even mortality, even before the introduction of LABA therapy. ${ }^{34}$ The potential of LABA to "mask" underlying inflammation because of increased symptom control and effect on lung function ${ }^{35}$ mandates that physicians ensure ICS doses are adequate to control airway inflammation.

\section{Is a further large LABA safety study justified?}

Essential criteria for a justifiable research study includes equipoise (the answer is not already known), feasibility (there are sufficient patients and resources to complete the study) and the likelihood that the study will provide an answer to the research question. Unfortunately, the new FDA study fails on each of these criteria.

To address asthma mortality with certainty, a large randomised controlled trial, powered on death as the primary outcome, in patients all using ICS would be necessary. Based on the RD of 0.25 per 1000 calculated by the FDA for the composite outcome among patients using mandated ICS, and the number of deaths included in the composite outcome, over four million subjects would need to be randomised. ${ }^{5}$ Including intubations and deaths, a clinically relevant trial outcome (five excess deaths or intubations) would require over 750000 subjects. Using the composite measure of deaths, intubations and hospitalisations as the outcome would certainly reduce the sample size, but would introduce major difficulties in interpretation. As already noted, several published analyses and meta-analyses, each using a subset of the data used by the FDA, have shown that LABA used with concomitant randomised ICS is either neutral in risk for exacerbations (dominantly hospitalisations), or in fact reduces the risk. ${ }^{17-22}$ Hence using the composite outcome would almost certainly produce results opposite to that suggested by the worst-case interpretation of the mortality data. Safety studies powered on exacerbations or hospital admissions are unnecessary and even unethical as clinical equipoise is lacking - the effect of adding LABA to adequate doses of ICS on these outcomes is already well documented.

The new FDA study is grossly underpowered for the outcome of interest, namely asthma death, and will take many years to complete. Countries outside the US have already accepted the safety of LABA used with mandatory ICS. Physicians with expertise in treating asthma within and outside the US use LABA confidently as add-on therapy to ICS, recognising that the initial concerns regarding adverse events were related to underuse of ICS. The multiple trials now available, and the benefits to patients previously struggling to achieve control with higher doses of ICS, have convinced consultant physicians and paediatricians that LABA therapy is efficacious and, with adequate ICS, is safe. Attempting to obtain new data from an impossibly large study may increase fear among patients, cause confusion among physicians and lead to inappropriate care for many asthmatics.

\section{PRACTICAL CONSIDERATIONS}

The LABAs under study include salmeterol, a partial agonist with a slower onset of action and formoterol, a more rapidly acting full agonist. One wonders how the data from differing LABAs and combinations with different ICS preparations will be able to be merged. What is being done to ensure adequate doses of ICS are used in the study?

The FDA in their 2008 meta-analysis of existing data showed conclusively that there was no safety signal when LABA and ICS were used as a combination in a single inhaler, yet has not 
mandated single-device combinations for all ages, but rather recommended this for children and adolescents. ${ }^{1}$ Are adults more compliant with multiple inhalers than teenagers and children? Fortunately, the use of a single inhaler is becoming the norm worldwide for the great majority of patients requiring both LABA and ICS therapies.

The new study will be large, long, resource-intensive and incredibly expensive. Given that we already know the only answer which will emerge from this study (that LABA added to ICS provides better control of asthma with fewer exacerbations than the same dose of ICS alone), one sadly muses on how else the dollars could have been spent-such as developing more effective medications, patient education, and promoting research to understand the fundamental causes of asthma which could eventually lead to its prevention or amelioration. Using these dollars to ostensibly obtain a definitive answer to a question that is already answered appears to many of us to be unjustified and an exercise in futility.

\section{REFERENCES}

1 Chowdhury BA, Dal Pan G. The FDA and safe use of long-acting beta-agonists in the treatment of asthma. N Engl J Med 2010;362:1169-71.

2 Chowdhury BA, Seymour SM, Levenson MS. Assessing the safety of adding LABAs to inhaled corticosteroids for treating asthma. N Engl J Med 2011;364:2473-5.

3 Drazen JM, O'Byrne PM. Risks of long-acting beta-agonists in achieving asthma control. N Engl J Med 2009;360:1671-2.

4 Beasley R, Martinez FD, Hackshaw A, et al. Safety of long-acting $\beta$-agonists: urgent need to clear the air remains. Eur Respir J 2009;33:3-5.

5 Sears MR. Safety of long-acting beta-agonists: are new data really required? Chest 2009;136:604-7.

6 Lemanske RF, Busse WW. The US Food and Drug Administration and long-acting $\beta_{2}$-agonists: the importance of striking the right balance between risks and benefits of therapy? J Allergy Clin Immunol 2010;126:449-52.

7 Greening AP, Wind P, Northfield M, et al. On behalf of the Allen and Hanburys Limited UK Study Group. Added salmeterol versus higher dose corticosteroid in asthma patients with symptoms on existing inhaled corticosteroids. Lancet 1994;344:219-24.

8 Woolcock A, Lundback B, Ringdal N, et al. Comparison of addition of salmeterol to inhaled steroid with doubling of the dose of inhaled steroids. Am J Respir Crit Care Med 1996:153:1481-8

9 Twentyman OP, Finnerty JP, Harris A, et al. Protection against allergen-induced asthma by salmeterol. Lancet 1990;336:1338-42.

10 Castle W, Fuller R, Hall J, et al. Serevent nationwide surveillance study: comparison of salmeterol with salbutamol in asthmatic patients who require regular bronchodilator treatment. Br Med J 1993;306:1034-7.

11 Nelson HS, Weiss ST, Bleecker ER, et al. The salmeterol multicenter asthma research trial: a comparison of usual pharmacotherapy for asthma or usual pharmacotherapy plus salmeterol. Chest 2006;129:15-26. [Erratum, Chest 2006:129:1393].

12 Mann M, Chowdhury B, Sullivan E, et al. Serious asthma exacerbations in asthmatics treated with high-dose formoterol. Chest 2003;124:70-4.

13 Salpeter SR, Buckley NS, Ormiston TM, et al. Meta-analysis: effect of long-acting $\beta$-agonists on severe asthma exacerbations and asthma-related deaths. Ann Intern Med 2006;144:904-12.

14 Hagan P. Four in five asthma deaths may be due to long-acting $\beta$ agonists. $B r$ Med J 2006;332:1467

15 Chinchilli VM. General principles for systematic reviews and meta-analyses and a critique of a recent systematic review of long-acting $\beta$-agonists. J Allergy Clin Immunol 2007:119:303-6.
16 Ernst P, Mclvor A, Ducharme FM, et al. Safety and effectiveness of long-acting inhaled $\beta$-agonist bronchodilators when taken with inhaled corticosteroids. Ann Intern Med. 2006;145:692-4.

17 Bateman $\mathrm{E}$, Nelson $\mathrm{H}$, Bousquet J, et al. Meta-analysis: effects of adding salmeterol to inhaled corticosteroids on serious asthma-related events. Ann Intern Med 2008; 149:33-42

18 Sears MR, Ottosson A, Radner F, et al. Long-acting beta-agonists: a review of formoterol safety data from asthma clinical trials. Eur Respir J 2009;33:21-32.

19 Nelson H, Bonuccelli C, Radner F, et al. Safety of formoterol in patients with asthma: combined analysis of data from double-blind, randomised controlled trials. $J$ Allergy Clin Immunol 2010;125:390-6.

20 Jaeschke $\mathrm{R}$, O'Byrne PM, Mezja F, et al. The safety of long-acting beta2-agonists among patients with asthma using inhaled corticosteroids. Systematic review and meta-analysis. Am J Respir Crit Care Med 2008;178:1009-16.

21 Rodrigo GJ, Moral VP, Marcos LG, et al. Safety of regular use of long-acting beta agonists as monotherapy or added to inhaled corticosteroids in asthma. A systematic review. Pulmon Pharmacol Therap 2009;22:9-19.

22 Cates CJ, Lasserson TJ, Jaeschke R. Regular treatment with salmeterol and inhaled steroids for cronic asthma: serious adverse events. Cochrane Database Syst Rev 2009;(3):CD006922

23 Levenson M. Long-Acting Beta-Agonists And Adverse Asthma Events Meta-Analysis. Statistical Briefing Package For Joint Meeting of the Pulmonary-Allergy Drugs Advisory Committee, Drug Safety and Risk Management Advisory Committee and Pediatric Advisory Committee. 2008. http://www.fda.gov/ohrms/dockets/ac/cder08. html\%23PulmonaryAllergy

24 Weatherall $\mathrm{M}$, Wijesinghe $\mathrm{M}$, Perrin $\mathrm{K}$, et al. Meta-analysis of the risk of mortality with salmeterol and the effect of concomitant inhaled corticosteroid therapy. Thoraz 2010:65:39-43.

25 Salpeter SR, Wall AJ, Buckley NS. Long-acting beta-agonists with and without inhaled corticosteroids and catastrophic asthma events. Am J Med 2010;123:322-8.e2

26 Kelsen SG, Church NL, Gillman SA, et al. Salmeterol added to inhaled corticosteroid therapy is superior to doubling the dose of inhaled corticosteroids: a randomised controlled trial. J Asthma 1999:36:703-15.

27 O'Byrne PM, Bisgaard H, Godard PP, et al. Budesonide/formoterol combination therapy as both maintenance and reliever medication in asthma. Am J Respir Crit Care Med 2005;171:129-36.

28 Ind PW, Dal Negro R, Colman NC, et al. Addition of salmeterol to fluticasone propionate treatment in moderate-to-severe asthma. Respir Med 2003;97: 555-62.

29 O'Byrne PM, Barnes PJ, Rodriguez-Roisin R, et al. Low dose inhaled budesonide and formoterol in mild persistent asthma: the OPTIMA randomised trial. Am J Respir Crit Care Med 2001;164:1392-7.

30 Kemp JP, Cook DA, Incuado GA, et al. Salmeterol improves quality of life in patiens with asthma requiring inhaled corticosteroids. Salmeterol Quality of Life Study Group. J Allergy Clin Immunol 1998;101:188-95.

31 Von Berg A, Papageorgiou Saxoni F, Wille $S$, et al. Efficacy and tolerability of formoterol Turbuhaler in children. Int J Clin Pract 2003;57:852-6.

32 Lemanske RF, Sorkness CA, Mauger EA, et al. Inhaled corticosteroid reduction and elimination in patients with persistent asthma receiving salmeterol. A randomised controlled trial. JAMA 2001; 285:2594-603.

33 Thomas $\mathrm{M}$, von Ziegenweidt J, Lee AJ, et al. High-dose inhaled corticosteroids versus add-on long-acting $\beta$-agonists in asthma: an observational study. J Allergy Clin Immunol 2009:123:116-21.

34 Suissa P, Ernst P. Inhaled corticosteroids: impact on asthma morbidity and mortality. J Allergy Clin Immunol 2001;107:937-44.

35 Mclvor RA, Pizzichini E, Turner MO, et al. Potential masking effects of salmeterol and airway inflammation in asthma. Am J Respir Crit Care Med 1998;158:924-30.

Competing interests None.

Provenance and peer review Commissioned; internally peer reviewed. 